\title{
Recovery of Value-Added Products from Hydrothermal Carbonization of Sewage Sludge
}

\author{
Pannarai Saetea and Nakorn Tippayawong \\ Department of Mechanical Engineering, Faculty of Engineering, Chiang Mai University, Chiang Mai 50200, Thailand \\ Correspondence should be addressed to Nakorn Tippayawong; n.tippayawong@yahoo.com
}

Received 3 May 2013; Accepted 5 June 2013

Academic Editors: D. Cazorla-Amoros, A. S. Chiang, and A. Ragauskas

Copyright (c) 2013 P. Saetea and N. Tippayawong. This is an open access article distributed under the Creative Commons Attribution License, which permits unrestricted use, distribution, and reproduction in any medium, provided the original work is properly cited.

\begin{abstract}
This paper is about the conversion of wet waste stream into valuable products via thermal processing. Hydrothermal carbonization of sewage sludge was carried out at $200^{\circ} \mathrm{C}$ and $2.1 \mathrm{MPa}$ in a closed reactor for 1-6 h. Main products were in solid and liquid phases. The resulting hydrochar was shown to have $\mathrm{H} / \mathrm{C}$ and $\mathrm{O} / \mathrm{C}$ ratios moving towards natural lignite, improved energetic content, and adsorption property in terms of iodine number. The aqueous solution was found to contain high concentration of plant food nutrients, especially nitrogen and potassium. They may be desirable for subsequent fuel and chemical production as well as applications in agriculture. The study shows that valuable products can be generated successfully from sewage sludge using hydrothermal carbonization.
\end{abstract}

\section{Introduction}

Sewage sludge is generated as an inevitable by-product of wastewater treatment activity. Their production is expected to rapidly increase with urbanization and industrial development. In Thailand, for example, about 4,000 tons per day of dry, treated sewage sludge solids is generated. Sewage sludge consists of mostly offensive and toxic substances. It must be disposed of or managed properly, otherwise, serious effects on humans and ecological systems will occur. Several methods can be adopted for the management of sewage sludge, such as landfill disposal, incineration, and utilization in agriculture, but each of these options has important limitations. Both incineration and landfill are troubled by their lowly public image. There are always concerns regarding associated costs and emissions. Application of sewage sludge to agricultural lands is restricted due to possible contamination of the soil and vegetation as well as hazardous consequences for animals and human. The decline of the traditional disposal routes for sewage sludge has created a strong demand for more cost effective and environmentally acceptable alternatives. This has motivated the research community to search for innovative and beneficial use of sewage sludge for years $[1,2]$.
A very appealing method is hydrothermal carbonization (HTC), also known as subcritical water or hot compressed water carbonization. It is ideal for high moisture content material such as sewage sludge. HTC can be described as a thermochemical process for converting an organic feedstock into value-added products, at moderate temperatures $\left(180-350^{\circ} \mathrm{C}\right)$ and pressures $(2-10 \mathrm{MPa})$ in the presence of liquid water. Hydrothermal degradation of organic matter and synthesis of basic chemicals and fuels have recently gained considerable scientific interests [3-6]. The use of char produced via HTC (i.e., hydrochar) has traditionally been focused on agronomic applications. Presently, it is possible to find a wide range of uses, mainly due to its properties and the diversity of materials that can be used in their synthesis. Consequently, hydrochars are regarded as valuable materials for various industrial, environmental, and agricultural applications. Proposed uses of hydrochar include an adsorbent, a carbon based smart material, an energy source, and a soil amendment agent [2-5, 7-18]. Typically, in comparison with pyrolysis chars, hydrochars have lower carbon content, less aromatic structure, and are less biologically stable [18], but the HTC process allows for higher carbon yield and overall energy efficiency when wet 
biomass is used. The significant benefits associated with HTC have led to a number of new research projects on waste stream carbonization $[5,18,19]$. HTC has shown enormous potential as a green waste conversion technique, ultimately converting waste materials to value-added products, while promoting carbon recovery in the solid phase [5, 18-20].

To date, there remain relatively few studies evaluating HTC of waste materials. Reported works on sewage sludge were even more limited. Notable studies on hydrothermal treatment of sewage sludge include Shanableh [21], Mumme et al. [22], and Escala et al. [23]. However, none of these works have reported extensively on the effect of reaction time coupled to the mild HTC condition. The main objective of the present work was to investigate the amenability of sewage sludge for hydrothermal carbonization and to obtain hydrochar that is a solid energy carrier with a low energy demand. The HTC process as well as the characteristics of the obtained hydrochar and the liquid filtrate product was the focus of this experimental study.

\section{Materials and Methods}

2.1. Raw Materials. Sewage sludge was obtained from a wastewater treatment plant of Chiang Mai University, Thailand. It was collected from the decantation and the secondary process and then subjected to anaerobic stabilization and drying. The waste sample was dried at $105^{\circ} \mathrm{C}$ for $4 \mathrm{~h}$ to achieve constant weight and then comminuted and sieved into a uniform size. It was ground to particle diameter of less than $1 \mathrm{~mm}$ and stored in a desiccator for later use. All chemicals used were of analytical grade from J. T. Barker, Co., Ltd. (Bangkok, Thailand).

2.2. Carbonization Process. The HTC experiments were carried out in a $1000 \mathrm{~mL}$ pressure reactor equipped with an external resistance heater and internal sensors for pressure and temperature. Dried sewage sludge $(100 \mathrm{~g})$ was dispersed in $300 \mathrm{~mL}$ of distilled water contained in a round-bottomed flask. Oxalic acid was used as a catalyst. It was added to the reactor at 1:1 catalyst to feed mass ratio. The mixture was shaken vigorously to create a homogeneous suspension. Its $\mathrm{pH}$ was about 6 . It was left at room temperature overnight, shaken again, and then transferred to the reactor. The heater was then switched on. The reactor was heated up to $200^{\circ} \mathrm{C}$ at a heating rate of about $5^{\circ} \mathrm{C} / \mathrm{min}$. It was kept at this condition for $1,2,4$, and $6 \mathrm{~h}$, after which the heater was turned off and the heat insulation was dismounted. The reactor was allowed to cool down for about $15 \mathrm{~h}$ to ambient condition.

The solid (hydrochar) and liquid products were collected and subsequently separated by filtration. The hydrochar was washed thoroughly with hot distilled water and dried in an oven for $4 \mathrm{~h}$ at $105^{\circ} \mathrm{C}$. At least three tests were performed for each condition. The hydrochar samples obtained were denoted according to carbonization time as $\mathrm{H}-1, \mathrm{H}-2, \mathrm{H}-4$, and $\mathrm{H}-6$, respectively.

2.3. Characterization of Products. The raw material and the hydrochars were analyzed for their chemical composition. Proximate analysis was conducted using a proximate analyzer model TGA 701, according to ASTM E 870-82, E 871-82, E 872-82, and D 1102-84 standards. The LECO elemental analyzers model CHNS-932 and model VTF-900 were employed for ultimate analysis according to ASTM D 3176 and E 775-87 standards. The surface morphology was studied by scanning electron microscopy. Hydrochar imaging was carried out using a JEOL JSM-5910 LV Scanning Electron Microscope. During the SEM analysis, char samples were selected and imaged randomly to minimize bias. Magnifications between $500 \mathrm{x}$ and 1,000x were typically used. The standard test method for the determination of adsorption characteristics in terms of iodine number of hydrochars was used (ASTM D 4607-94, 2002).

Kjeldahl method, molybdenum-blue method, and atomic emission spectroscopy (Perkin Elmer ICP-AES model Optima 3000) were used to determine the nutrient content of the liquid product. The interesting elements in this study were $\mathrm{N}$, P, and $\mathrm{K}$. All analytical determinations were performed in triplicate and average results were presented.

\section{Results and Discussions}

3.1. Hydrochars. Characteristics of sewage sludge and its hydrochars were evaluated to study the changes of the raw material with respect to energy-related properties and chemical components. Against dried sewage sludge, Table 1 shows solid yields, ultimate analysis, proximate analysis, and heating value of the hydrochars.

For the raw material, it was observed that the dried sewage sludge had low fixed carbon but notably high fractions of ash $(40 \%)$ and volatile organic matter $(>50 \%)$. The hydrochar yields obtained from the HTC were dependent on the carbonization time, in the $74-81 \%$ range. Standard deviations of the mean yields are also shown. The values here were higher than those reported by Mumme et al. [22] and Escala et al. [23] whose yields of sludge hydrochars were $36-72 \%$ and $56-69 \%$, respectively. It should be noted that treatment conditions were not exactly similar. However, the trend was clear that higher recovery of solid product was found at shorter reaction time. Increasing the carbonization time led to a slight decrease in yield due to larger overall decomposition of biomass material, or because carbon, existing in sewage sludge as volatile matter, progressively reacted and diffused out. The increase in fixed carbon and the decrease in volatile matter content between the raw materials and hydrochars confirmed that carbonization took place. For the first $60 \mathrm{~min}$, only volatile matter at the surface was removed. At longer reaction times, volatile matter in the interior of the particle would be removed, but with more difficulty than at the surface. The fixed carbon content from HTC was increased from 8.6 to 9.3, 12.2, 13.9, and 14.2\% for $\mathrm{H}$ $1, \mathrm{H}-2, \mathrm{H}-4$, and H-6, respectively. A significant shift in fixed carbon content was not expected, due to an originally high ash content and mild HTC conditions applied.

Change in elemental composition of the solid material was observed as a result of carbonization (Table 1). HTC of the sewage sludge led to an increase in the carbon content of the solid residue from $49 \%$ (sewage sludge) to $56-58 \%$ in the hydrochar samples. The high fraction of carbon was retained 
TABLE 1: Chemical characteristics and properties of dried sewage sludge and its hydrochars from $\mathrm{HTC}$ at $200^{\circ} \mathrm{C}$ and $1-6 \mathrm{~h}$.

\begin{tabular}{|c|c|c|c|c|c|}
\hline & Sewage sludge & $\mathrm{H}-1$ & $\mathrm{H}-2$ & $\mathrm{H}-4$ & $\mathrm{H}-6$ \\
\hline Yield (\% w/w) & - & $81.2 \pm 0.4$ & $80.0 \pm 1.1$ & $77.1 \pm 0.9$ & $73.6 \pm 0.5$ \\
\hline \multicolumn{6}{|l|}{ Elemental analysis (\%) } \\
\hline $\mathrm{C}$ & 49.3 & 57.6 & 56.1 & 58.1 & 57.1 \\
\hline $\mathrm{H}$ & 7.0 & 6.4 & 6.7 & 6.4 & 6.8 \\
\hline $\mathrm{N}$ & 8.4 & 4.2 & 3.8 & 4.2 & 4.5 \\
\hline $\mathrm{O}$ & 34.0 & 32.6 & 31.0 & 30.2 & 29.6 \\
\hline$S$ & 1.3 & 1.1 & 1.0 & 1.1 & 1.0 \\
\hline \multicolumn{6}{|l|}{ Proximate analysis (\%) } \\
\hline Ash & 40.0 & 50.6 & 49.7 & 48.7 & 48.4 \\
\hline Volatile matter & 51.5 & 39.8 & 37.9 & 37.4 & 37.2 \\
\hline Fixed carbon & 8.6 & 9.3 & 12.2 & 13.9 & 14.2 \\
\hline $\mathrm{HHV}(\mathrm{MJ} / \mathrm{kg})$ & 20.6 & 22.8 & 23.0 & 23.4 & 23.7 \\
\hline Energy densification & - & 1.11 & 1.12 & 1.14 & 1.15 \\
\hline Energy recovery (\%) & - & 91.3 & 90.1 & 88.7 & 85.4 \\
\hline
\end{tabular}

in the hydrochar products, while the rest mainly remained in the organic compounds that dissolved in the aqueous, similar to those reported in the literature $[24,25]$. It should be noted that gas generation from HTC was generally small (2-5\%), according to Escala et al. [23] and Lu et al. [26]. There was slight reduction in the oxygen and hydrogen contents. These variations are consistent with the formation of a less condensed material. Chemical transformation of organic material to carbon rich material or coalification process may be presented using a van Krevelen diagram [3]. Atomic H/C and $\mathrm{O} / \mathrm{C}$ ratios for sewage sludge and its hydrochars were plotted in Figure 1, along with other substances (cellulose, lignite, and subbituminous coals) for comparison. Pathways for demethanation, dehydration, and decarboxylation were also illustrated. It was observed that the $\mathrm{H} / \mathrm{C}$ and $\mathrm{O} / \mathrm{C}$ ratios decreased after $\mathrm{HTC}$, due mainly to dehydration and decarboxylation. Similar trend was reported by Parshetti et al. [27] for similarly mild HTC condition $\left(150^{\circ} \mathrm{C}, 20 \mathrm{~min}\right)$. It was likely that further carbonization was possible to increase the extent of coalification. At more severe HTC conditions (higher temperatures or longer times), the $\mathrm{H} / \mathrm{C}$ and $\mathrm{O} / \mathrm{C}$ ratios of hydrochars were expected to approach the values similar to those associated with lignite and subbituminous coals. A significant advantage of HTC process is its simplicity that it only involves heating biomass in water in a confined system. Reaction temperature selected was $200^{\circ} \mathrm{C}$ because carbonization at this condition was reported to be able to sufficiently generate product that is well qualified and similar to coal quality [24]. Higher temperatures would increase reaction pressure significantly, resulting in increased cost and complexity of processing equipment. However, it was clear that at the mild HTC condition considered here, reaction times of up to $6 \mathrm{~h}$ did not affect chemical composition of the final products significantly. The hydrochars produced showed only slight change in compositions for all conditions considered.

Analysis of hydrochar energetic content is also shown in Table 1. High heating value (HHV) was calculated based

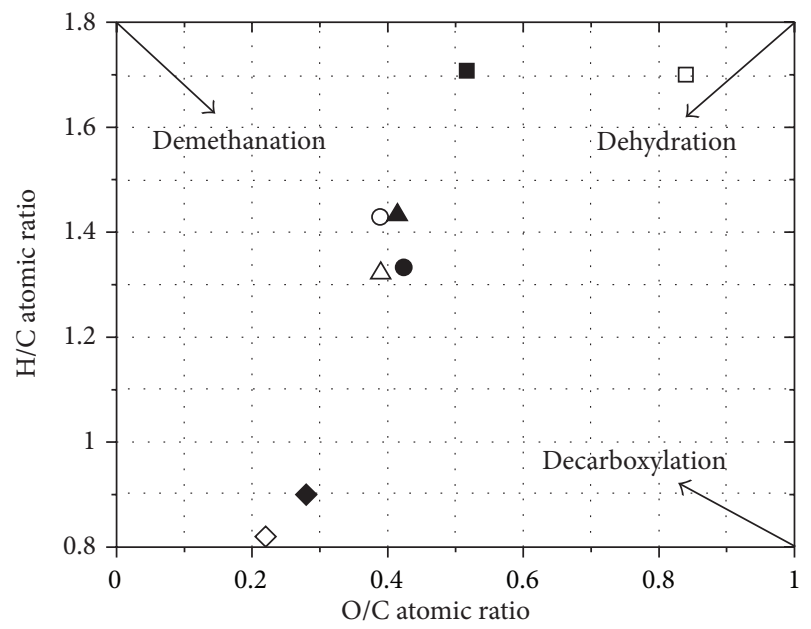

FIGURE 1: van Krevelen diagram of the sewage sludge $(\boldsymbol{\square})$ and its

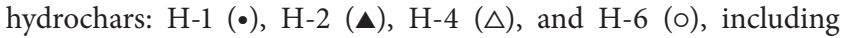
data of cellulose $(\square)$, lignite $(\checkmark)$, and subbituminous $(\diamond)$ coals for comparison. The arrows represent demethanation, dehydration, and decarboxylation pathways.

on Dulong's formula. Energy densification was defined as an $\mathrm{HHV}$ ratio between the hydrochar and the starting material. The calculated HHV and energy densification factor were found to increase with increasing carbonization time, showing ranges of $22.8-23.7 \mathrm{MJ} / \mathrm{kg}$ and $1.11-1.15$, respectively. This observation was in line with the increase in carbon content of the hydrochars, as both HHV and carbon are an indication of the degree of coalification obtained. With respect to the energy recovery factor, defined as a ratio between energy content in the hydrochar divided by that in the sewage sludge, it was found to be high, ranging from 85 to $91 \%$.

At a fixed reaction temperature, reaction time was expected to have an influence on hydrochar microscopic properties. Images of representative sewage sludge and hydrochar are shown in Figure 2. From a close inspection 


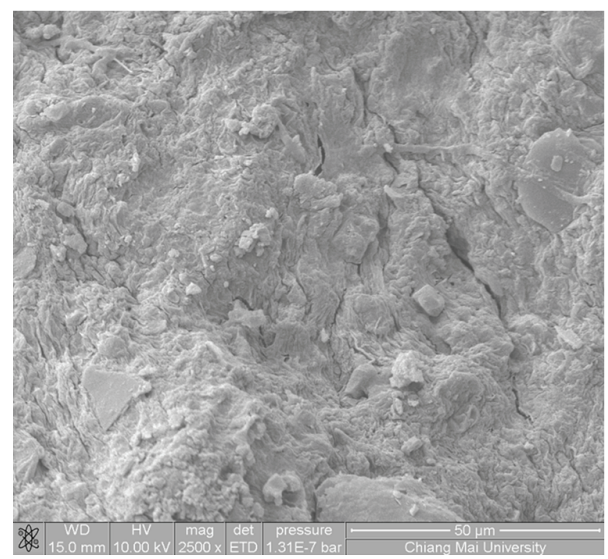

(a)

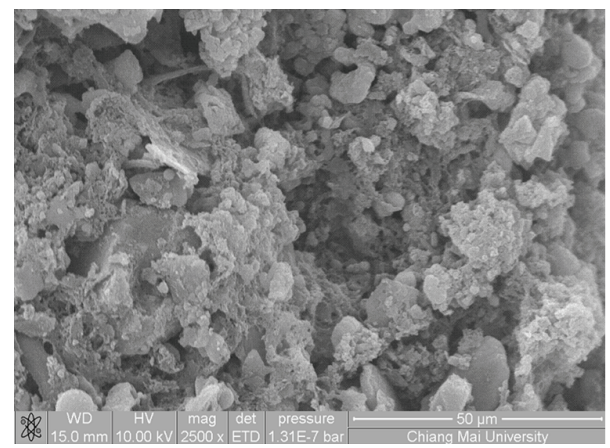

(b)

FIgURE 2: SEM images of (a) dried sewage sludge and (b) resulting hydrochars.

with SEM, a clear difference in surface morphology between the hydrochar and the sewage sludge was observed, showing the rupture of structure due to HTC process. The hydrochar appeared to be in brownish black color, suggesting that it was not completely carbonized. It also showed a more uneven and rougher surface than the raw material. The breakdown of the structure may be contributed to full or partial degradation of remaining lignocellulosic components of the raw material.

Iodine number is normally used as an indication of adsorption ability of a particular material. Iodine number of dried sewage sludge was found to be $93 \pm 4 \mathrm{mg} / \mathrm{g}$. Figure 3 shows the results of iodine adsorption capability of hydrochars. The HTC process proved to develop porosity of dried sewage sludge. A high iodine number of about $222 \pm 12 \mathrm{mg} / \mathrm{g}$ was found at $1 \mathrm{~h}$. It decreased with increasing the reaction time. The HTC temperature used here was not enough to drive the inner volatile matter and tar out. Tar and volatile matter in the pores may block the diffusion of the reacting agent into the structure. Thus, only limited numbers of pores were developed. Hence, as HTC time increased, iodine absorption capacity decreased dramatically because small pore structure was destroyed, resulting in larger pores. As a result, the ability to absorb iodine decreased. Low porosity of hydrochar implicated here was consistent with those reported by Parshetti et al. [27] and Mumme et al. [22]. The high temperature and long reaction times were

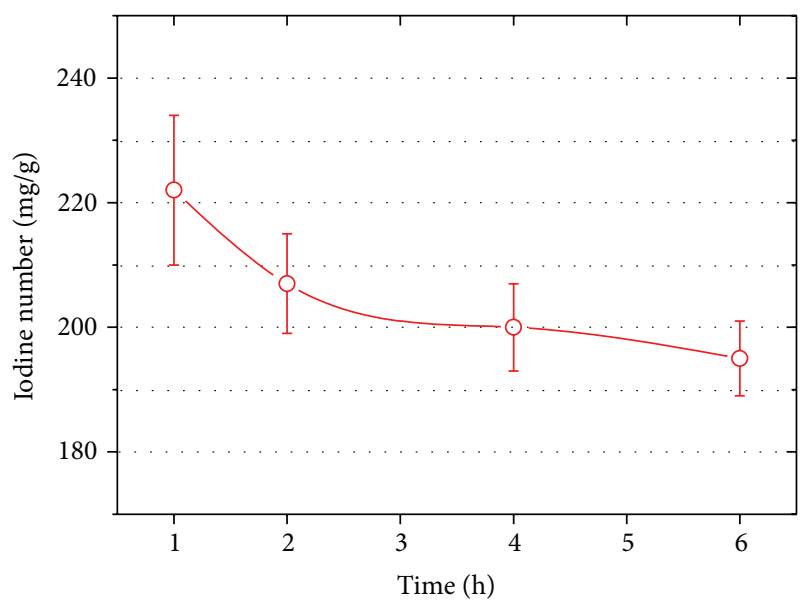

FIGURE 3: Effect of HTC time on iodine adsorption ability of hydrochars.

TABLE 2: Properties of liquid by-products from HTC at $200^{\circ} \mathrm{C}$ and $1-6 \mathrm{~h}$.

\begin{tabular}{lcccc}
\hline & L-1 & L-2 & L-4 & L-6 \\
\hline $\mathrm{N} \mathrm{(mg/L)}$ & $2392 \pm 10$ & $2393 \pm 12$ & $2396 \pm 11$ & $2419 \pm 15$ \\
$\mathrm{P}(\mathrm{mg} / \mathrm{L})$ & $804 \pm 8$ & $809 \pm 11$ & $811 \pm 6$ & $813 \pm 10$ \\
$\mathrm{~K}(\mathrm{mg} / \mathrm{L})$ & $1516 \pm 12$ & $1516 \pm 9$ & $1517 \pm 8$ & $1519 \pm 11$ \\
\hline
\end{tabular}

unfavorable for the porous structure of the char. The porous structure cracked, and the pores might be partially blocked as a result of the softening and melting of the material constituents, leading to a poor surface property [24].

3.2. Liquid Filtrate By-Product. It is generally known that water plays a significant role as a solvent and reactant in the HTC process. The liquid phase is expected to contain a high load of organics and inorganics. It may be recycled as a nutrient solution to agricultural lands. The liquid filtrate obtained was completely sterile after the $\mathrm{HTC}$ at $200^{\circ} \mathrm{C}$. A slight drop in $\mathrm{pH}$ of the aqueous phase was observed after $\mathrm{HTC}$ reaction. It is noted here that original $\mathrm{pH}$ of deionized water was neutral. The liquid phase was found to be acidic which can be explained by the formation of a variety of organic acids that typically occur during the HTC process. In this work, analysis of the liquid product from HTC of sewage sludge was carried out for nutrient content. Results are shown in Table 2 . The liquid phase was found to contain high values of potassium and nitrogen, while the phosphorus was relatively low. These findings were in qualitative agreement with those by Escala et al. [23]. Longer reaction time at this mild HTC condition did not appear to affect the recovery of nutrient content significantly. Further investigation on contents of heavy metals is needed if this liquid product is to be beneficial for reuse in agriculture.

\section{Conclusion}

In this work, hydrothermal carbonization of sewage sludge has been carried out. The waste can be thermally converted 
into carbonaceous solid product with high yields of $74-81 \%$. The resulting hydrochar had a higher energetic content and better adsorption capability than the starting raw material. Longer carbonization times increased the hydrochar's fixed carbon and carbon content but decreased its yields and iodine adsorption ability. The sterile liquid product contained high nutrients. This work demonstrated that the HTC process offers attractive and alternative technique for the conversion of sewage sludge to value-added products. Further works may be performed to gain better understanding of the underlying process, to characterize related properties, and to identify applications for these products.

\section{Acknowledgments}

The authors would like to thank the Department of Scientific Services, Ministry of Science and Technology, and the Mae Moh Laboratory, Electricity Generating Authority of Thailand, for technical support.

\section{References}

[1] S. Krigstin and M. Sain, "Fractionation of dry recycled papermill sludge to higher value components," Journal of Biobased Materials \& Bioenergy, vol. 1, no. 3, pp. 315-322, 2007.

[2] K. M. Smith, G. D. Fowler, S. Pullket, and N. J. D. Graham, "Sewage sludge-based adsorbents: a review of their production, properties and use in water treatment applications," Water Research, vol. 43, no. 10, pp. 2569-2594, 2009.

[3] M. Sevilla and A. B. Fuertes, "The production of carbon materials by hydrothermal carbonization of cellulose," Carbon, vol. 47, no. 9, pp. 2281-2289, 2009.

[4] M. M. Titirici and M. Antonietti, "Chemistry and materials options of sustainable carbon materials made by hydrothermal carbonization," Chemical Society Reviews, vol. 39, pp. 103-116, 2010.

[5] A. Funke and F. Ziegler, "Hydrothermal carbonization of biomass: a summary and discussion of chemical mechanisms for process engineering," Biofuels, Bioproducts and Biorefining, vol. 4, no. 2, pp. 160-177, 2010.

[6] H. A. Ruiz, R. M. Rodriguez-Jasso, B. D. Fernandes, A. A. Vicente, and J. A. Teixeira, "Hydrothermal processing as an alternative for upgrading agriculture residues and marine biomass according to the biorefinery concept: a review," Renewable \& Sustainable Energy Reviews, vol. 21, pp. 35-51, 2013.

[7] Q. Wang, H. Li, L. Chen, and X. Huang, "Monodispersed hard carbon spherules with uniform nanopores," Carbon, vol. 39, no. 14, pp. 2211-2214, 2001.

[8] X. Cui, M. Antonietti, and S.-H. Yu, "Structural effects of iron oxide nanoparticles and iron ions on the hydrothermal carbonization of starch and rice carbohydrates," Small, vol. 2, no. 6, pp. 756-759, 2006.

[9] M.-M. Titirici, A. Thomas, and M. Antonietti, "Back in the black: hydrothermal carbonization of plant material as an efficient chemical process to treat the $\mathrm{CO}_{2}$ problem?" New Journal of Chemistry, vol. 31, no. 6, pp. 787-789, 2007.

[10] M. M. Titirici, A. Thomas, S.-H. Yu, J.-O. Müller, and M. Antonietti, "A direct synthesis of mesoporous carbons with bicontinuous pore morphology from crude plant material by hydrothermal carbonization," Chemistry of Materials, vol. 19, no. 17, pp. 4205-4212, 2007.

[11] D. Cao, Y. Sun, and G. Wang, "Direct carbon fuel cell: fundamentals and recent developments," Journal of Power Sources, vol. 167, no. 2, pp. 250-257, 2007.

[12] R. Demir-Cakan, N. Baccile, M. Antonietti, and M.-M. Titirici, "Carboxylate-rich carbonaceous materials via one-step hydrothermal carbonization of glucose in the presence of acrylic acid," Chemistry of Materials, vol. 21, no. 3, pp. 484-490, 2009.

[13] J. P. Paraknowitseh, A. Thomas, and M. Antonietti, "Carbon colloids prepared by hydrothermal carbonization as efficient fuel for indirect carbon fuel cells," Chemistry of Materials, vol. 21, no. 7, pp. 1170-1172, 2009.

[14] M. Sevilla and A. B. Fuertes, "Chemical and structural properties of carbonaceous products obtained by hydrothermal carbonization of saccharides," Chemistry, vol. 15, no. 16, pp. 4195-4203, 2009.

[15] B. Hu, K. Wang, L. Wu, S.-H. Yu, M. Antonietti, and M.-M. Titirici, "Engineering carbon materials from the hydrothermal carbonization process of biomass," Advanced Materials, vol. 22, no. 7, pp. 813-828, 2010.

[16] M. C. Rillig, M. Wagner, M. Salem et al., "Material derived from hydrothermal carbonization: effects on plant growth and arbuscular mycorrhiza," Applied Soil Ecology, vol. 45, no. 3, pp. 238242, 2010.

[17] M. Sevilla, A. B. Fuertes, and R. Mokaya, "High density hydrogen storage in superactivated carbons from hydrothermally carbonized renewable organic materials," Energy and Environmental Science, vol. 4, no. 4, pp. 1400-1410, 2011.

[18] J. A. Libra, K. S. Ro, C. Kammann et al., "Hydrothermal carbonization of biomass residuals: a comparative review of the chemistry, processes and applications of wet and dry pyrolysis," Biofuels, vol. 2, no. 1, pp. 71-106, 2011.

[19] N. D. Berge, K. S. Ro, J. Mao, J. R. V. Flora, M. A. Chappell, and S. Bae, "Hydrothermal carbonization of municipal waste streams," Environmental Science and Technology, vol. 45, no. 13, pp. 56965703, 2011.

[20] I.-H. Hwang, H. Aoyama, T. Matsuto, T. Nakagishi, and T. Matsuo, "Recovery of solid fuel from municipal solid waste by hydrothermal treatment using subcritical water," Waste Management, vol. 32, no. 3, pp. 410-416, 2012.

[21] A. Shanableh, "Production of useful organic matter from sludge using hydrothermal treatment," Water Research, vol. 34, no. 3, pp. 945-951, 2000.

[22] J. Mumme, L. Eckervogt, J. Pielert, M. Diakité, F. Rupp, and J. Kern, "Hydrothermal carbonization of anaerobically digested maize silage," Bioresource Technology, vol. 102, no. 19, pp. 92559260, 2011.

[23] M. Escala, T. Zumbuhl, Ch. Koller, R. Junge, and R. Krebs, "Hydrothermal carbonization as an energy efficient alternative to established drying technologies for sewage sludge: a feasibility study on a laboratory scale," Energy \& Fuels, vol. 27, pp. 454460, 2013.

[24] S. M. Heilmann, H. T. Davis, L. R. Jader et al., "Hydrothermal carbonization of microalgae," Biomass and Bioenergy, vol. 34, no. 6, pp. 875-882, 2010.

[25] S. M. Heilmann, L. R. Jader, M. J. Sadowsky, F. J. Schendel, M. G. von Keitz, and K. J. Valentas, "Hydrothermal carbonization of distiller's grains," Biomass and Bioenergy, vol. 35, no. 7, pp. 2526-2533, 2011. 
[26] X. Lu, B. Jordan, and N. D. Berge, "Thermal conversion of municipal solid waste via hydrothermal carbonization: comparison of carbonization products to products from current waste management techniques," Waste Management, vol. 32, no. 7, pp. 1353-1365, 2012.

[27] G. K. Parshetti, S. K. Hoekman, and R. Balasubramanian, "Chemical, structural and combustion characteristics of carbonaceous products obtained by hydrothermal carbonization of palm empty fruit bunches," Bioresource Technology, vol. 135, pp. 683-689, 2012. 

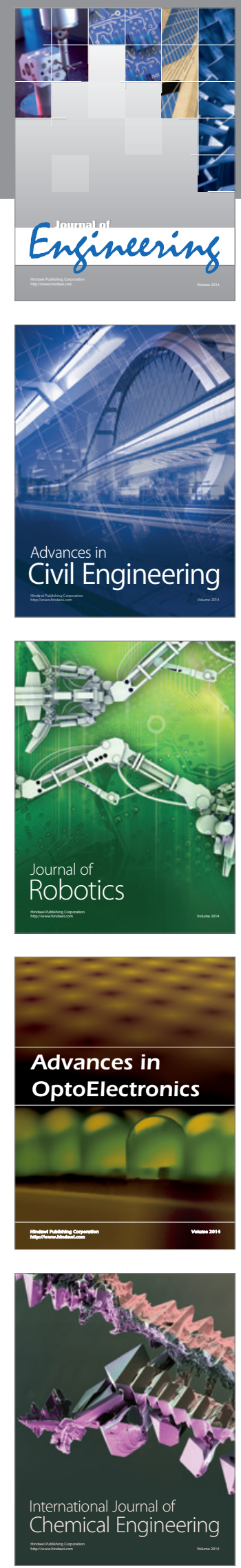

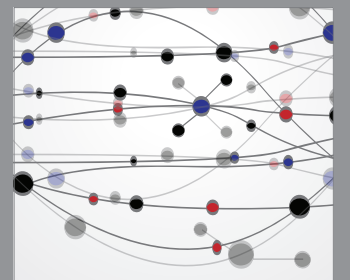

The Scientific World Journal
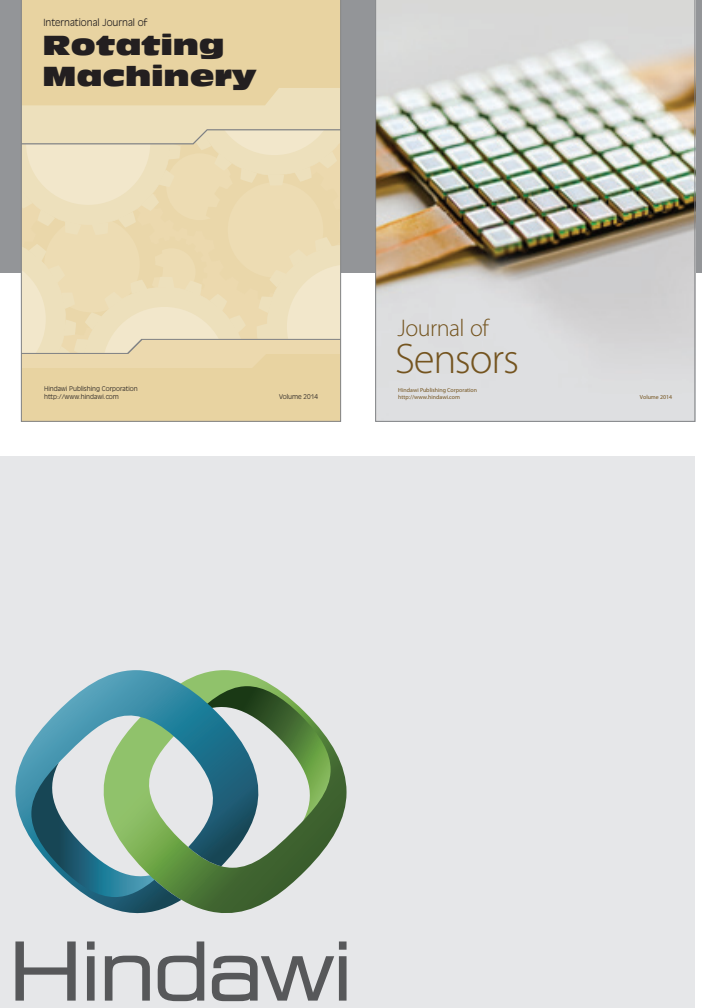

Submit your manuscripts at http://www.hindawi.com
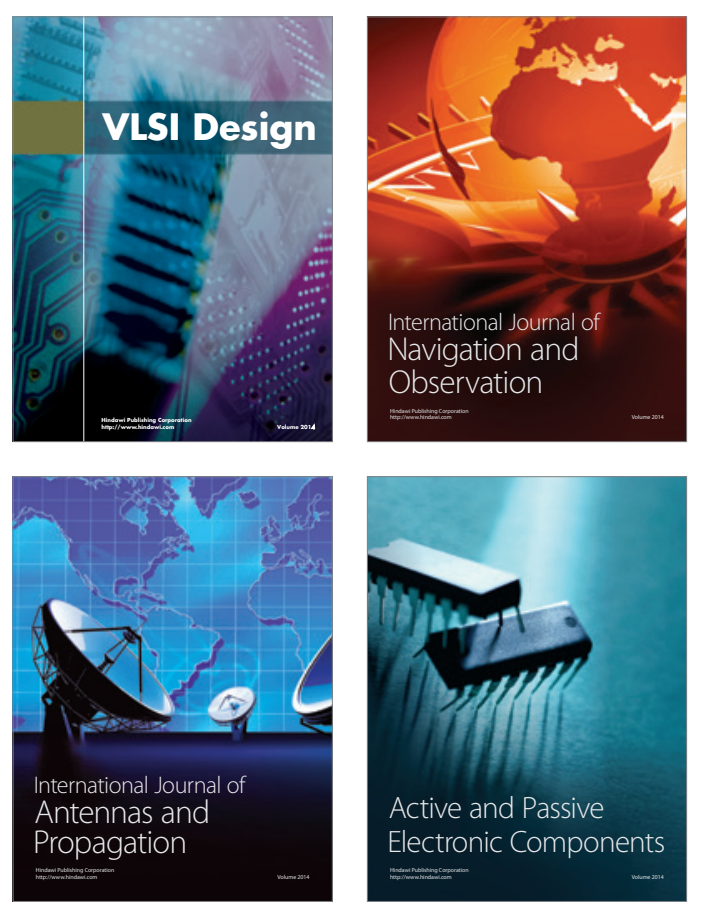
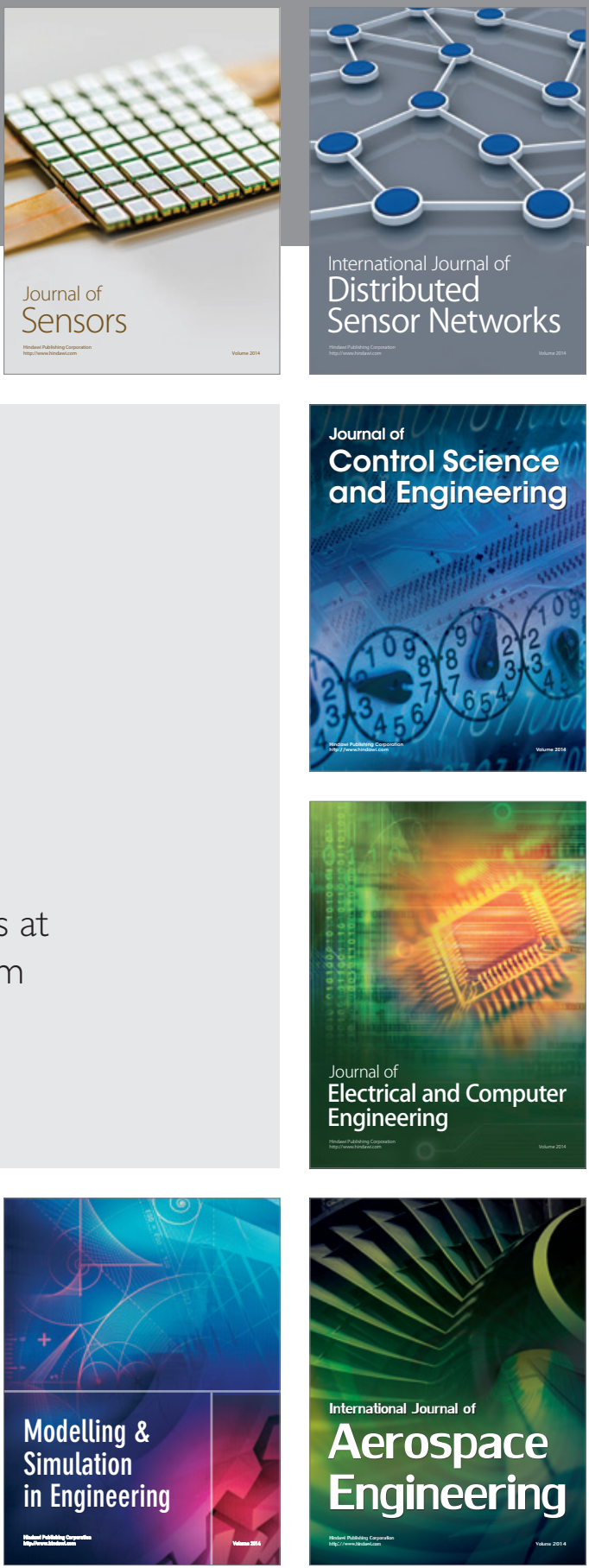

Journal of

Control Science

and Engineering
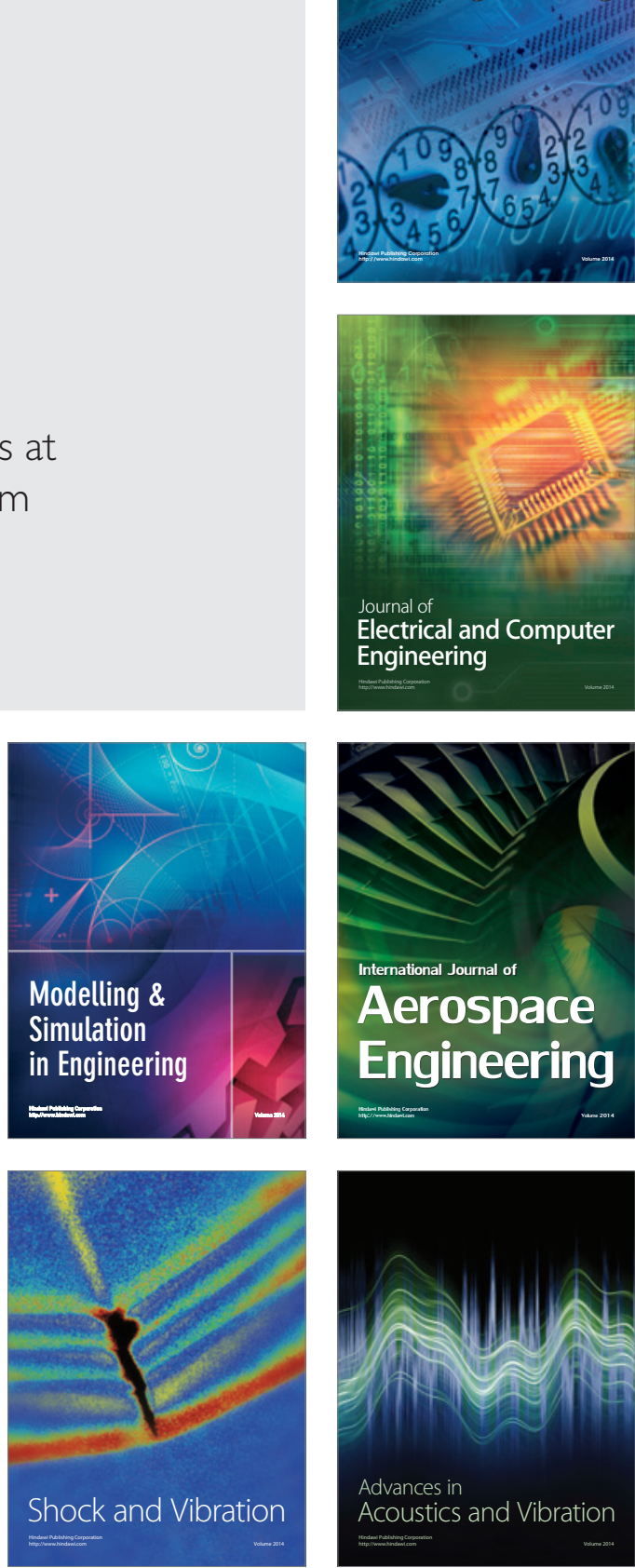